This chapter details the process the University of Michigan developed to build institutional capacity for learning analytics. A symposium series, faculty task force, fellows program, research grants, and other initiatives are discussed, with lessons learned for future efforts and how other institutions might adapt such efforts to spur cultural change to utilize institutional data to improve teaching and learning processes.

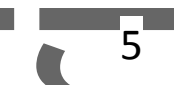

\title{
Cultivating Institutional Capacities for Learning
}

\section{Analytics}

\section{Steven Lonn, Timothy A. McKay, and Stephanie D.}

\section{Teasley}

As the 21st century neared, many large U.S. postsecondary institutions began to reevaluate their longheld practices of maintaining student records. Computerized systems became the norm; institutions began developing electronic student information systems (SISs) to record and store student records. However, many institutions failed to realize the potential for research on teaching and learning outcomes that lay within SISs and other enterprise technology systems. At the University of Michigan (U-M), there was some early interest in this data by designing a basic query tool for faculty to visualize simple frequencies and correlations (Academic Reporting Toolkit, circa 2002), but the data mainly languished in separate and unintegrated, institutional databases for each functional area (admissions, registration, human resources, research, and so on).

Two early efforts at U-M laid the groundwork for the later analytics community. First, inspired by work by Freeman and colleagues (2007) that predicted student performance in introductory biology using GPA and SAT scores, three physics faculty members investigated student performance in physics courses, identified those who did better and worse than predicted and investigated potential reasons why (Wright, McKay, Hershock, Miller, \& Tritz, 2014). Second, the USE Lab, an interdisciplinary research lab investigating the intersection of learning technologies in higher education teaching led by Stephanie Teasley, a research professor in the School of Information, conducted a series of studies investigating perceptions and aggregated use of the institutional learning management system (for example, Lonn \& Teasley, 2009).

While these early efforts at U-M were primarily faculty-led, a variety of academic and support staff as well as students of alt levels need to be involved in creating a culture of awareness and acceptance for learning

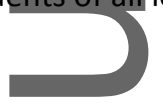

This is the an manuscript accepted for publication and has undergone full peer review but has not been thi woh th copyediting, typesetting, pagination and proofreading process, which may lead to differences betm this version and the Version of Record. Please cite this article as doi: 10.1002/he.20243.

This article is protected by copyright. All rights reserved. 
analytics (Arnold, Lonn \& Pistilli, 2014). Cultivating institutional capacities from these members of the university community can, and should, include a variety of opportunities, at multiple levels of engagement, in order to elicit the broadest possible support from the institutional community of scholars, researchers, and professionals. While not the only blueprint for such cultural development, the authors of this chapter detail the various components of the efforts undertaken at the University of Michigan from 2011 to 2015 so other institutions may reflect on the lessons learned and adopt or adapt similar efforts to their own institutional contexts.

\section{The Origin of the Symposium on Learning Analytics at Michigan and the Cearning Analytics Community}

The University of Michigan, like many large U.S. higher education institutions with very high research activity, is highly decentralized. Interactions among faculty members, particularly across disciplinary lines, are often haphazard and unplanned. This was the case for the two faculty members at the epicenter of the launch of the learning analytics community at U-M in early 2011. Timothy McKay, an Arthur F. Thurnau Professor of Physics and Astronomy, had recently been awarded a Next Generation Learning Challenge (NGLC) Grant from the Bill \& Melinda Gates Foundation to launch ECoach, a tailored message tool to guide students through physics classes using analytics-powered algorithms and personalized testimonials. Meanwhile, Teasley's USE Lab had recently launched Student Explorer, an early warning system that gathered data from the institutional learning management system and delivered categorized warning signals to students' academic advisors, who could then interpret and act upon the simplified data presentation.

These professors, and their projects, were introduced via a mutual colleague (thanks to Ann VerheyHenke) as word of McKay's NGLC grant spread among faculty involved in technology initiatives at U-M. Seeing an opportunity to not only share insights among known colleagues but also build a community around the nascent field of academic and learning analytics, McKay and Teasley submitted a proposal to U-M's Rackham Graduate School and Office of the Vice-President for Research to launch an interdisciplinary seminar series (McKay \& Teasley, 2011). The proposal highlighted the promise of bringing new techniques to bear on student data:

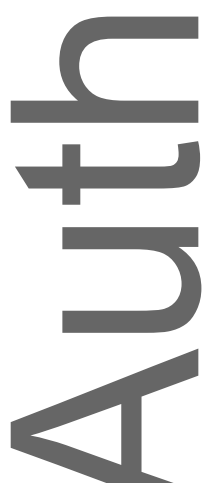

Mining available data and using academic analytics can provide a rich portrait of each student's progress through the university; a map of their journey from application, through the curriculum, to graduation. Performance at every stage is recorded, at a minimum as course grades, but often in more detailed ways. ... This information can tell us a tremendous amount about how students progress from naïve beginners to graduates, how they navigate the university, and how they learn.

The proposal also highlighted the fact that the necessary expertise about learning theory, student success, data mining, visualization, and predictive modeling is diffused across many domains at an institution 
like U-M. The central idea was to bring together students, faculty, and staff interested in analytics in a compelling series of seminars that would spur future collaborations and research projects.

This symposium proposal was accepted and planning began in earnest to line up internal and external speakers. MeKay and Steven Lonn, a postdoctoral scholar in Teasley's research lab, assumed much of the planning responsibilities, focusing mainly on educational research projects across multiple disciplines that could be considered early learning analytics projects. Lonn suggested the acronym SLAM for the "Symposium on Learning Analytics at Michigan."

SLAM launched on September 14, 2011, with several dozen U-M faculty, students, and staff in attendance to hear McKay discuss this new series and his own work investigating years of physics students at U-M (Miller, 2011). This led to the creation of the ECoach project. U-M chemistry researchers and the director of U-M's writing center followed in subsequent SLAM sessions. External speakers John Campbell from Purdue University and David Pritchard from the Massachusetts Institute of Technology rounded out the first five sessions of SLAN

Lonn recorded all of the first-year SLAM talks and slides on an institutional website to serve as an archive and learning materials for the U-M community. In all, 14 internal and three external speakers or teams presented in the first year of SLAM-all of whose presentations and materials are available today as a nationally visible resource (Center for Research on Learning and Teaching, 2017). As the learning analytics community at U-M grew, this historical record was valuable to understand the context and growing institutional-knowledge in this emergent field.

\section{Establishing a Learning Analytics Task Force}

With the aim of growing and supporting a larger learning analytics research community at U-M, McKay reached out to campus leadership to provide funding and a process to foster early learning analytics-related investigations. As Cameron (1984) writes, higher education institutions often respond to complexity in their environment by producing new complex local structures for task management. Learning analytics, specifically, requires leadership to navigate significant and strategic changes to organizational culture and behavior (Baepler \& Murdoch, 2010; Norris, Baer, \& Offerman, 2009). McKay, a longtime faculty member at U-M and an established leader in a variety of administrative committees, was therefore a perfect fit to champion the launch of learning analytics efforts at a large and diverse research university like U-M.

After the first successful semester of the SLAM series, McKay met with the university provost, Philip Hanlon, to discuss support for learning analytics at U-M. McKay had served on the faculty governance's Academic Affairs Advisory Committee that had recently completed an internal assessment report that highlighted the various ways data was used at the institution, particularly in the area of increasing methodologies and techniques to analyze large amounts of student data. Hanlon committed \$2 million of internal funds to support learning analytics through the establishment of a 3-year faculty governance body: the Learning Analytics Task Force (LATF) (McKay, 2012).

This article is protected by copyright. All rights reserved. 
Chaired by McKay, the LATF membership comprised 12 faculty members from a cross-section of disciplines-an early attempt to reflect the cross-disciplinary interest in learning analytics. The LATF was charged with "designing a program of activities to draw out, support, and execute the best ideas in learning analytics at Michigan." Three primary goals were included in this charge: (1) explore the U-M information environment and recommend to the Provost improvements to make U-M a world-class environment for learning analytics research, (2) design and execute a funding program to support the best learning analytics projects proposed by the university community, and (3) review the metrics used to assess teaching and learning at U-M.

In support of these goals, the LATF supported several major activities. First, the SLAM seminars would continue under the auspices of the U-M Center for Research on Learning and Teaching. Between 2012 and 2015, 37 different presentations were offered from internal and external speakers and teams. Nearly 2,000 attendees representing nearly every school and college at U-M engaged with the presenters in real time, and all of the presentations were recorded and materials provided online. These videos, on topics such as improving peer education through analytics and using learning analytics in pedagogical design, have received over 8,500 total views worldwide. The 4 years of SLAM were instrumental in providing a space for learning, sharing insights, and engaging with leading researchers - it is doubtful that the learning analytics community today at U-M would be as disciplinarily diverse without the SLAM series as an initial catalyst.

\section{University of Michigan-Funded Learning Analytics Grants}

In support of its charge to design and execute a funding program to support analytics projects, the LATF created two programs to facilitate the growing learning analytics research community at U-M. For researchers and teams who were ready to launch a significant research project, the Exploring Learning Analytics (ELA) grant program provided both financial (up to $\$ 150,000$ ) and technical support. ELA grants were designed to support the analysis of data generated in academic activities at U-M with the goal of better understanding teaching and learning on campus, and to contribute intellectually to the U-M learning analytics community.

\footnotetext{
ELA grant proposals were evaluated on a quarterly basis during the first year and a half of the LATF tenure, allowing time for funded proposals to report on initial findings. Proposals were evaluated on several criteria including the potential impact on the student experience, the potential to expand and improve the use of learning analytics, the appropriateness of the project team to meet its stated goals, and the contribution to the interdisciplinary mix of ELA projects. In all, 16 proposals were received, resulting in eight funded ELA projects:

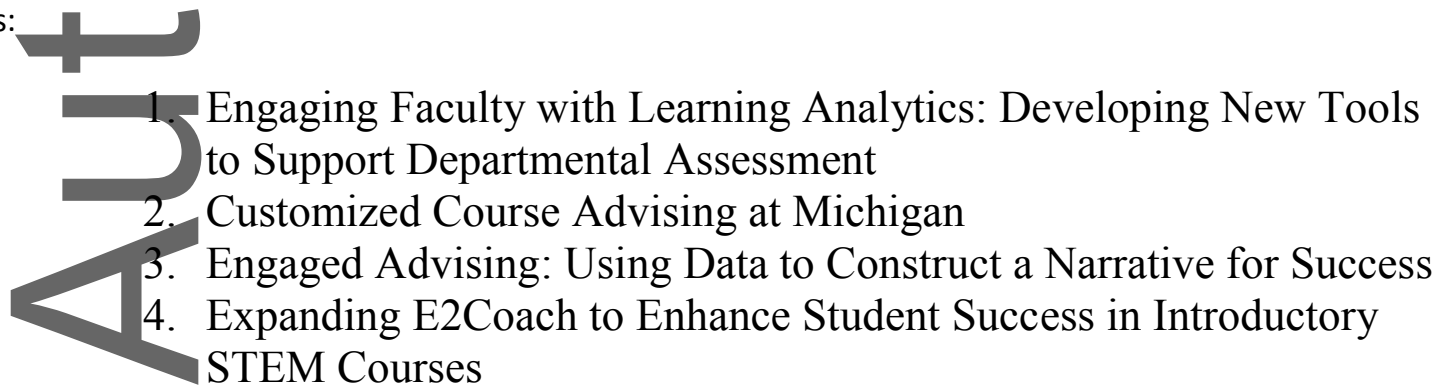

5. Library Analytics for Student Success

This article is protected by copyright. All rights reserved. 


\section{Arts at Michigan: Arts Engagement Project}

7. Using LA to Coach Students to "Electrifying" Careers

8. Playful Analytics: Infusing a Learning Management System with Analytics that Motivate Learning and Support Teaching

The results of these eight projects varied from uncovering previously unknown facts and trends about student learning and performance to new tools and techniques for analyzing data. For example, the "Customized Course Advising" project revealed that engineering freshmen who received a 4 on their Math $A B$ Advanced Placement exam only received an A or B grade $50 \%$ of the time when enrolling in Calculus II their first term (Nam, Lonn, Brown, Davis, \& Koch, 2014). This finding resulted in academic advisors' critical analysis of students' math placement exam scores before recommending an initial math course to students. Several ELA projects investigated the use and outcomes from developing analytics-powered tools including ECoach, Student Explorer, and GradeCraft, a new learning management system for gameful course environments. In all, the ELA projects were instrumental in advancing the analysis and tools of learning analytics research at U$M$, particularly when paired with the LATF's other funding program: the learning analytics fellows.

\section{The Learning Analytics Fellows Program}

Recognizing that growing a learning analytics research community included not only providing funds for projects but also providing a learning environment in which to foster the development of learning analytics skills and knowledge, the LATF launched the learning analytics fellows program in January 2013. The call for applications was released in November 2012 for both junior (graduate students and postdoctoral scholars) and senior (faculty and staff) fellows. Fellows were required to meet weekly throughout the winter semester; discuss methodological, ethical, policy, and pedagogical issues and implications of analytics research; attend SLAM seminars; and work on small-scale research projects to develop research plans. Each junior fellow received $\$ 2,000$ and each senior fellow received $\$ 4,000$ cash stipends to support their analytics efforts (for example, paying for temporary student help, professional development, and so on).

The winter 2013 cohort of learning analytics fellows consisted of 15 junior fellows and 16 senior fellows. The syllabus for this initial cohort included an introduction to institutional data sets, course recommender systems, data visualization, course-level data, noncognitive factors, the institutional review board (IRB) and the Family Educational Rights and Privacy Act (FERPA), and data ethics and privacy. Many of the fellows in this initial class used the funds to support their initial research ideas or later submitted proposals for ELA grants and other national grants. For example, three of the fellows from the Chemistry Department (Shultz, Winschel, \& Gottfried, 2015) analyzed the impact of a general chemistry prerequisite on later student achievement and progression in subsequent chemistry courses.

The winter 2014 cohort of learning analytics fellows was deliberately smaller (19 fellows). The call for fellows explicitly solicited teams of junior and senior members who specified a nascent project idea that they would like to explore during the semester. The syllabus in the second cohort also reflected the growing breadth and varied interests of the community - the topics included natural language processing, prediction models, dashboards, learning measurements, stereotype threat, and behavioral change. Again, the projects

This article is protected by copyright. All rights reserved. 
developed during the cohort led to several grant proposals and scholarly papers (for example, Brooks, Chavez, Tritz \& Teasley, 2015).

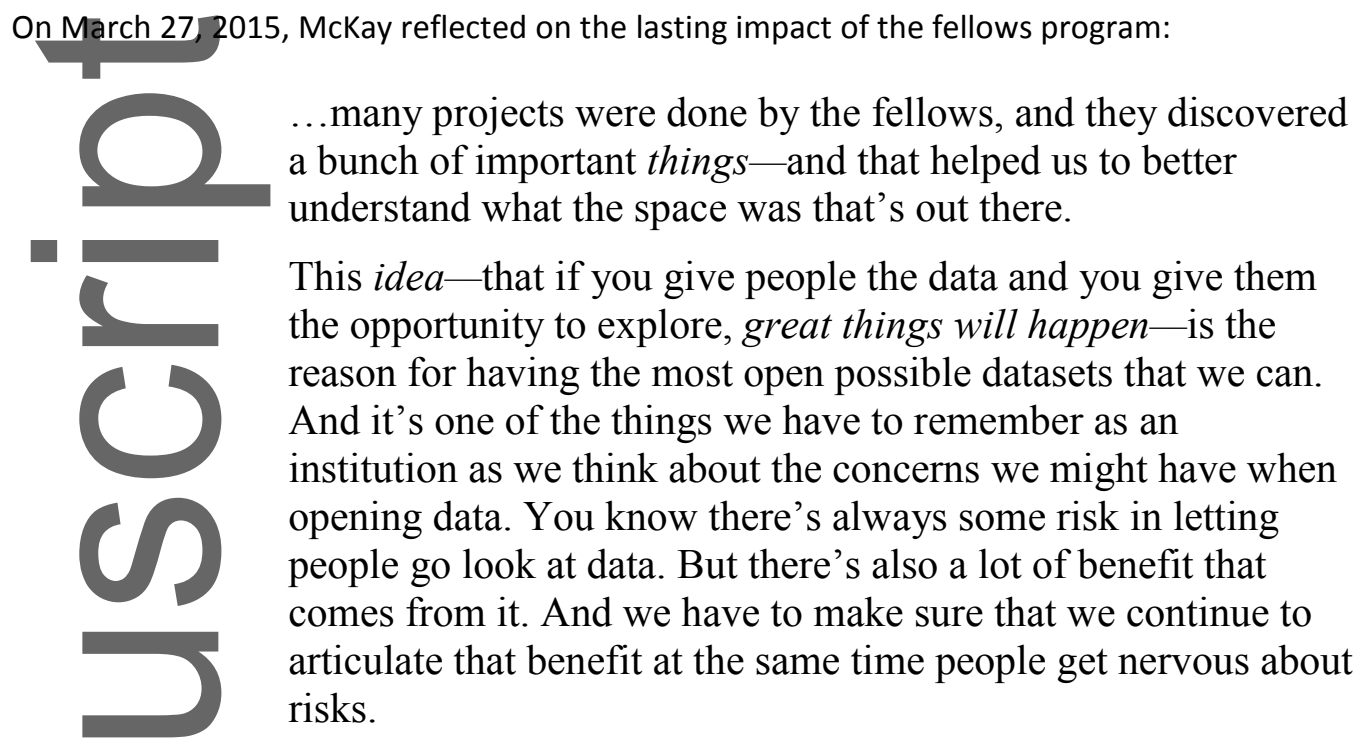

The learning analytics fellows program also had several tangible results that helped streamline the process to connect $\mathrm{U}-\mathrm{M}$ researchers to the appropriate institutional data to answer their learning analytics questions. First, the IRB became much more attuned to the nature and types of research questions that are typical in learning analytics research, and thus better able to direct researchers to appropriate approval processes for those projects that could typically be considered exempt from ongoing IRB review and those that needed to follow the nonexempt review process. Second, the Office of General Council developed a streamlined memorandum of understanding document for the fellows program that defined how the fellows were to comply with FERPA and data security standards. Finally, Lonn, recognizing a demonstrated need for more normalized institutional data for learning analytics research, began to work with analytics researchers and institutional technology staff members to develop and maintain a new learning analytics data architecture dataset to support the next generation of learning analytics research initiatives (see

https://enrollment.umich.edu/data-research/learning-analytics-dataarchitecture-larc).

New Metrics, Cross-Institutional Research, and Analytics-Driven Culturäl Change

The third charge of the LATF was to review the metrics used to assess teaching and learning at U-M. To that end, a subcommittee of the LATF investigated the core teaching evaluation questions filled out by students at the end of every course. This project found that evaluations were fairly consistent and were significantly correlated with evaluations posted on the RateMyProfessors website. One significant outcome from this project was the recognition that the existing university-wide standard questions did not reflect the types of teaching and learning outcomes that the faculty sought to recognize. After a report to the faculty 
governance body and significant deliberation, a new set of eight evaluation questions (four old, four new) were developed and established as of fall term 2016 to better reflect a variety of dimensions about each learning environment.

After the first year of the SLAM seminars, McKay presented the concept of the LATF and the learning analytics efforts at U-M to a meeting of all of the provosts in the Big Ten Academic Alliance. The provosts endorsed an effort to compare learning analytics metrics and also encouraged McKay to explore ways to scale the learning analytics fellows model. In partnership with U-M colleagues Jason Owen-Smith and Margaret Levenstein, McKay received a grant from the Sloan Foundation to extend across the Big Ten institutions the analysis his research group had completed as part of the LATF efforts (Koester, Grom \& McKay, 2016). Meeting in August 2014, the gathered attendees agreed on four research areas: (1) compare and contrast differences between students' incoming GPA and received grades in various course types, (2) explore course sequences and when students' declare different majors, (3) investigate students' persistence within degree programs and differences across disciplines, and (4) examine how students engage in federally funded research projects and the courses students enroll in to participate in directed research. Participants reconvened in November 2014 to discuss preliminary results. As one example, five institutions reported similar results when investigating gendered performance differences in introductory STEM courses. Other projects being considered include how the Big Ten or other higher education consortia might collaboratively build a multi-institutional dataset providing a larger picture of the impact of research universities.

Another key project that took place during the LATF's charge was a \$2 million grant from the National Science Foundation awarded to McKay and colleagues to support analytics-powered reform efforts in introductory physics, biology, chemistry, and mathematics courses. This project connected departmental teams and allowed them to reevaluate curricula, instructional modes, and other elements of the learning environments while carefully considering all the underlying data. As a result, using data to support pedagogical decisions in these departments has become the norm and is credited for making broad, and relatively fast, changes to foundational courses. The impact of these projects on the U-M community aligns closely with findings from similar projects undertaken at other Big Ten universities, as noted by colleagues at Purdue University: "the institutional application of analytics can result in a major shift for colleges and universities with regard to the culture fostered around undergraduate learning" (Pistilli, Willis, \& Campbell, 2014, p. 88).

C

\section{Finding New Homes for Continuing Learning Analytics Task Force Efforts}

As the LATF's 3 -year charge came to a close, the committee sought to institutionalize or find new homes for many of the efforts that successfully fostered the emergent learning analytics research community. In an effort to help scale the learning analytics fellows concept beyond U-M, McKay developed a massive open online course entitled Practical Learning Analytics, now available on the EdX platform. This course offers a flexible, collaborative introduction to learning analytics in higher education in which students learn by doing, using realistic data and code. Course materials are intended to support groups of faculty and staff who might create their own learning analytics fellows program.

This article is protected by copyright. All rights reserved. 
Institutional support for new, innovating learning analytics projects has migrated to U-M's new Michigan Institute for Data Science (MIDAS). In June 2016, MIDAS announced that learning analytics was one of their four designated thrust areas and two new projects had been launched, one analyzing students' written work and behavioral data and the other investigating connections between students' values and beliefs and their success in higher education.

While MIDAS has been organized around research using data science techniques, the role for continuing a broad, faculty-led effort to investigate learning analytics issues and questions has been charged to the new U-M Institutional Learning Analytics (UMILA) group. Cochaired by McKay and former U-M provost Paul Courant, UMILA consists of nine faculty members who work along with academic administrative leaders to identify the-areas of learning analytics research that would most deeply influence decision making at administrative levels of the university.

Finally, the SLAM series, which had run for 4 years, has been reimagined as a working research group focused on methodological and technical issues in the Academic Innovation at Michigan Analytics series, supported by the new Office of Academic Innovation. This office also houses the new Digital Innovation Greenhouse, an incubator designed to broadly scale analytics-powered digital tools for teaching and learning. This new office, along with MIDAS and UMILA, has provided continuing institutional support for learning analytics and has begun to grow the community beyond the faculty, students, and staff who regularly attended the SLAM seminars.

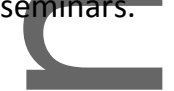

\section{Conçusion}

The rise of scholarly research and institutionally actionable uses of learning analytics at the University of Michigan was built on a number of activities supported by key stakeholders. These include faculty leaders who engaged in related scholarly research, an IT infrastructure that provided access to necessary student-level data, an informed IRB and Office of General Council who helped guide the conditions for ethical use of the data under FERPA, and a central administration that provided financial support that allowed community building through public talks, a fellows program, and seed money for emerging projects. While an institution need not employ all of the various components and initiatives that U-M has supported thus far, these activities have been instrumental in building a broad and visible interdisciplinary community across a large research university.

The impact of this effort has been recognized beyond campus. In 2016, the Society for Learning Analytics Research (SoLAR) invited U-M to host their summer institute annually, and Teasley was elected to be the next president of the society. Regardless of the specific initiatives taken, academic institutions are well served bypromoting the growth of a community of scholars and practitioners interested in leveraging institutional-data to improve student learning. Engaging faculty and students to explore and uncover new insights in student learning can fundamentally transform the culture of a postsecondary institution toward continuous, evidence-informed improvement of teaching and learning processes.

References

This article is protected by copyright. All rights reserved. 
Arnold, K. E., Lonn, S., \& Pistilli, M. D. (2014). An exercise in institutional reflection: The Learning Analytics Readiness Instrument (LARI). In A. Pardo \& S. Teasley (Eds.), Proceedings from the Fourth International Conference on Learning Analytics and Knowledge (pp. 163-167). New York, NY: ACM. doi: $10.1145 / 2567574.2567621$

Baepler, P., \& Murdoch, C. J. (2010). Academic analytics and data mining in higher education. International Journal for the Scholarship of Teaching and Learning, 4(2), 1-9. doi:

10.20429/ijsotl.2010.040217

Brooks, C., Chavez, O., Tritz, J., \& Teasley, S. D. (2015). Reducing selection bias in quasi-experimental educational studies. Proceedings of the Fifth International Conference on Learning Analytics \& Knowledge (pp. 295-299). New York, NY: ACM. doi: 10.1145/2723576.2723614

Cameron, K.S. (1984). Organizational adaptation and higher education. Journal of Higher Education, 55(2), 122-144. Retrieved from

http://www.tandfonline.com/doi/abs/10.1080/00221546.1984.11778679

Center for Research on Learning and Teaching. (2017). Student Learning and Analytics at Michigan

(SLAM). Retrieved from http:// crlt.umich. edu/slam?tid\%5B\%5D=420

Freeman, S., O'Conhor, E., Parks, J. W., Cunningham, M., Hurley, D. H., Haak, D., . . Wenderoth, M. P. (2007). Prescribed active learning increases performance in introductory biology. CBE-Life Sciences Education, 6(2), 132-139. doi: 10.1187/cbe.06-09-0194

Koester, B. P., Grom, G., \& McKay, T. A. (2016). Patterns of gendered performance difference in introductory STEM courses. Retrieved from https: / / arxiv.org/abs/1608.07565

Lonn, S., \& Teasley, S. D. (2009). Saving time or innovating practice: Investigating perceptions and uses of learning management systems. Computers \& Education, 53(3), 686-694. doi:

10.1016/j.compedu.2009.04.008

McKay, T. A. (2012). The University of Michigan Learning Analytics Task Force: 2012-2015. Retrieved from https://sites.google.com/a/umich.edu/um-latf/

McKay, T. A., \& Teasley, S. D. (2011). Rackham interdisciplinary seminar proposal: Academic analytics: Interdisciplinary data mining to improve student learning. Retrieved from

http://hdl.handle.net/2027.42/134731

Miller, K. (2011). Gender matters: Assessing and addressing the persistent gender gap in physics education. University of Michigan Honors Senior Thesis. Retrieved from

http://hdl.handle.net/2027.42/85304

Nam, S., Lonn, S., Brown, T., Davis, C. S., \& Koch, D. (2014). Customized course advising: Investigating engineering student success with incoming profiles and patterns of concurrent course enrollment. Proceedings of the Fourth International Conference on Learning Analytics and Knowledge (pp. 1625). New York, NY: ACM. doi: 10.1145/2567574.2567589

This article is protected by copyright. All rights reserved. 
Norris, D., Baer, L., \& Offerman, M. (2009). A national agenda for action analytics. Paper presented at the National Symposium on Action Analytics, Minneapolis, MN, September. Retrieved from

http://lindabaer.efoliomn.com/uploads/settinganationalagendaforactio nanalytics101509.pdf

Pistilli, M. D., Willis, III, J. E., \& Campbell, J. P. (2014). Analytics through an institutional lens: Definition, theory, design, and impact. In J. A. Larusson \& B. White (Eds.), Learning analytics: From research to practice (pp. 79-101). New York, NY: Springer. doi: 10.1007/978-1-4614-3305-7_5

Shultz, G. V., Winschel, G. A., \& Gottfried, A. (2015). The impact of general chemistry prerequisite on student achievement and progression to subsequent chemistry courses: A regression discontinuity analysis. Journal of Chemical Education, 92(9), 1449-1455. doi: 10.1021/acs.jchemed.5b00209 Wright, M. C., McKay, T., Hershock, C., Miller, K., \& Tritz, J. (2014). Better than expected: Using learning analytics to promote student success in gateway science. Change: The Magazine of Higher Learning, 46(1), 28-34. doi: 10.1080/00091383.2014.867209

STEVEN LONN is the Director of Enrollment Research and Data Management in the Office of Enrollment Management at the University of Michigan.

TIMOTHY A. MCKAY is an Arthur F. Thurnau Professor of Physics, Astronomy, and Education and the Faculty Director of the Digital Innovation Greenhouse at the University of Michigan.

STEPHANIE D. TEAsLeY is a Research Professor in the School of Information and the Director of the Learning, Education and Design Lab at the University of Michigan.

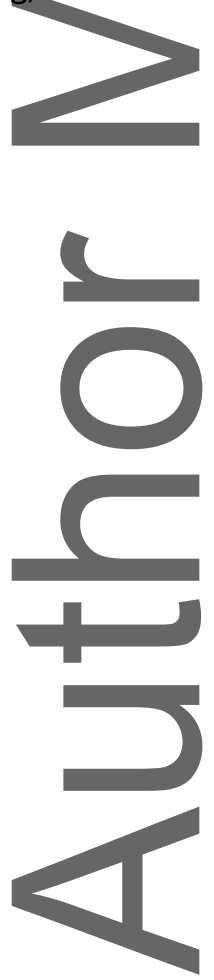

This article is protected by copyright. All rights reserved. 